\title{
Aggregate matching in Spain. Time series analysis using cointegration techniques
}

\author{
Ewa Gałecka-Burdziak'
}

\begin{abstract}
I analyze the matching process in the Spanish labor market from 1994-2005. I use monthly registered unemployment data and refer solely to public employment intermediation. This period reflects an upward movement along a downward sloping Beveridge curve; therefore, major changes in the process efficiency should not be observed. I narrow the considerations to a job queuing model, which is the most relevant description of the labor market matching process in Spain, according to the literature. I apply various quantitative methods to address the problem of non-stationary data. The EngleGranger estimates emphasize the crucial role of the demand in generating the outflows from unemployment to employment. The ECT coefficient confirms that the model efficiently approaches the new equilibrium. These findings confirm that job seekers find themselves on the disadvantaged side of the market and compete for scarce job offers, which, in turn, are ascribed randomly to the workers. The diagnostic tests of the VAR models question the relevance of a multivariate space analysis because the outflow from unemployment to employment appears to be the sole endogenous variable.
\end{abstract}

KEY WORDS: $\quad$ labor market matching, job queuing model, time series analysis, Spanish labor market

JEL Classification: J63; J64

${ }^{1}$ Department of Economics I, Warsaw School of Economics, Poland

\section{Introduction}

Trade occurs constantly in a labor market and leads to matches between job seekers and vacancies. Trade occurs randomly or non-randomly and can be formally presented by a matching function. In this article, I focus on a technical perspective of the matching process. Most often, the log-linear specification (with constant returns to scale restriction imposed) is assumed, and

Correspondence concerning this article should be addressed to: Ewa Gałecka-Burdziak, Department of Economics I, Warsaw School of Economics, ul. Madalińskiego 6/8, 02-513Warsaw, Poland, phone: +48 225649322 E-mail: ewa.galecka-burdziak@sgh.waw.pl the coefficients are estimated by the OLS estimator (Petrongolo \& Pissarides 2001). Soininen (2006) notes that empirical research relatively rarely refers econometrically to a non-stationary time series. Among the few papers using Engle-Granger or Johansen approaches, one can distinguish, for example: (Albaek \& Hansen, 2004; Archambault \& Fortin, 2001; Blanchard \& Diamond, 1989; de Francesco, 1999; Soininen, 2006), and for Spain, in particular, Bell (1997) and Gałecka-Burdziak (2013).

I use various econometric methods, including cointegration techniques, to contribute to the robustness of the results that concern the matching process in Spain. I begin with the single equation model using Engle- 
Granger and Engle-Yoo procedures. The estimated coefficients can be interpreted as the outflow elasticities with respect to unemployment or vacancy pools that are of main interest in the matching function analysis. Next, I extend the analysis to the multivariate perspective. I develop VAR models to analyze the interdependence among the variables to describe the labor market matching process. I choose a country from the Iberian Peninsula because the data characteristics allow for a precise public employment intermediation description. I choose the time span, 1994-2005, which reflects an upward movement along a downward sloping Beveridge curve. Thus, we can expect homogenous trade technology with no major changes in the trade process efficiency. The recession, which Spain experienced at the beginning of the 1990s, ended in 1993. In May 2005, a new methodology of gathering data was implemented; this introduces a breakthrough in the data (since then, there have been no comparable data on vacancies registered at public employment offices because each offer can consist of the numerous job posts).

The Spanish labor market has endured fundamental changes concerning legal conditions because the implementation of the new constitution in 1978. Spain joined the European Economic Community in 1986 and implemented a series of reforms with the objective of increasing the elasticity of the market, encouraging companies to create better quality jobs and hiring workers on permanent contracts (e.g., reforms implemented in 1984, 1994, 1997 and 2001). Among the outcomes of these changes, one can list the duality of the labor market; this originates from the extensive use of temporary contracts (approximately $25 \%$ in 2010 ) and the high volatility of (un)employment. Petrongolo and Pissarides (2008) prove that both unemployment inflow and outflow contribute to high unemployment volatility.

One can find a few literature surveys that concern the matching function estimates for the Spanish labor market, for example: (Alujas Ruiz, 2002; Álvarez de Toledo, Núñez and Usabiaga, 2004; 2008; Núñez, 2006; Núñez \& Usabiaga, 2007). The main qualitative conclusions arise from using registered data. Antolín (1994) proposes a method to recalculate the vacancy data for the entire economy (but for a stock-based model). The analyses imply that vacancies are the driving force of the outflow from unemployment to employment creation. Moreover, the findings indicate that the job queuing model, which assumes random matching between unemployment stock and vacancy inflow, most properly describes the public employment intermediation in Spain.

This paper is organized as follows. In section 2, I present data. Section 3 includes a univariate space analysis using Engle-Granger and Engle-Yoo techniques. I refer to the job queuing model to present matching between the stock of the job seekers and the inflow of new vacancies. I extend the dimension of the analysis in section 4, in which I apply the Johansen approach. In section 5, I interpret the results and compile concluding remarks in section 6 .

\section{Data characteristics}

I base quantitative analysis on the registered unemployment and vacancy data from public employment offices (Servicio Público de Empleo Estatal). These time series possess certain valuable features. Companies are obliged to register each job offer (as a vacancy or as a covered job post). The outflow from unemployment to employment can be directly assigned to public employment intermediation, which refers to the job offers registered at public employment offices. Once we compare this time series with the total hires, we can assess the fraction of the total job creation that arises from public employment offices intermediation.

Table 1 compiles summary statistics for the selected variables: the outflow from unemployment to employment generated through public employment intermediation $(M)$, unemployment stock $(U)$, total job seekers stock $(J)$, unemployment inflow $(u)$ and vacancy variables, stock $(V)$ and inflow $(v)$. The time series are seasonally adjusted.

Job seeker stocks possess distinctions from the other variables features. These time series decrease during the chosen time span, whereas the others generally rise. The means are higher than the medians for the job seekers stocks, and both time series are right skewed. The other variables are left skewed, excluding the vacancy stock, which is nearly symmetric. The coefficient of variation is the lowest for job seekers stocks. A relatively low variation is further confirmed by the turnover indices. Vacancies are more volatile and should enjoy a lower expected duration. The time series display a high degree of persistence. 
Table 1. Main statistical properties of the variables, 1994-2005

\begin{tabular}{|c|c|c|c|c|c|c|}
\hline & $O \rightarrow E$ & $U$ & $J$ & $u^{\mathrm{a}}$ & $V$ & $v$ \\
\hline mean & 152296 & 1906811 & 3540272 & 392099 & 94560 & 168378 \\
\hline median & 172814 & 1682303 & 3196175 & 404939 & 102657 & 199315 \\
\hline $\min$ & 27211 & 1509629 & 2944337 & 224557 & 16010 & 27861 \\
\hline $\max$ & 247456 & 2705753 & 4766034 & 491944 & 215337 & 264115 \\
\hline stand. dev. & 55528 & 376350 & 559615 & 58272 & 51387 & 65009 \\
\hline coef. of variation & 0.365 & 0.197 & 0.158 & 0.149 & 0.543 & 0.389 \\
\hline monthly autocor. & 0.945 & 0.981 & 0.979 & 0.937 & 0.958 & 0.950 \\
\hline \multicolumn{7}{|l|}{ average turnover } \\
\hline$\frac{\text { unempl. inflow }}{\text { unempl. stock }}$ & - & 0.22 & 0.12 & - & - & \\
\hline$\frac{\text { vacancy inflow }}{\text { vacancy stock }}$ & - & - & - & - & 2.05 & \\
\hline no. of observations & 136 & 136 & 136 & 136 & 136 & 136 \\
\hline
\end{tabular}

a - data re-estimated (compare Álvarez de Toledo et al. (2008)).

Source: Author's own calculation on the basis of Database published by Servicio Público de Empleo Estatal (2012).

Table 2. Unit root tests results

\begin{tabular}{|c|c|c|c|c|c|c|}
\hline & $M$ & $U$ & $J$ & $u^{\mathrm{b}}$ & $V$ & $v$ \\
\hline $\begin{array}{l}\text { ADF } \\
\text { (p-value) }\end{array}$ & $\begin{array}{l}-2.18 \\
(0.22)\end{array}$ & $\begin{array}{l}-2.98 \\
(0.04)\end{array}$ & $\begin{array}{l}-3.72 \\
(0.00)\end{array}$ & $\begin{array}{l}-1.92 \\
(0.32)\end{array}$ & $\begin{array}{l}-1.46 \\
(0.55)\end{array}$ & $\begin{array}{l}-2.23 \\
(0.20)\end{array}$ \\
\hline $\begin{array}{l}\text { ADFa } \\
\text { (p-value) }\end{array}$ & $\begin{array}{r}-14.94 \\
(0.00)\end{array}$ & $\begin{array}{l}-1.94 \\
(0.05)\end{array}$ & $\begin{array}{l}-1.95 \\
(0.05)\end{array}$ & $\begin{array}{r}-15.03 \\
(0.00)\end{array}$ & $\begin{array}{r}-10.90 \\
(0.00)\end{array}$ & $\begin{array}{r}-14.09 \\
(0.00)\end{array}$ \\
\hline $\begin{array}{l}\text { Phillips-Perron } \\
\text { (p-value) }\end{array}$ & $\begin{array}{l}-2.21 \\
(0.20)\end{array}$ & $\begin{array}{l}-3.17 \\
(0.02)\end{array}$ & $\begin{array}{l}-3.55 \\
(0.01)\end{array}$ & $\begin{array}{l}-2.08 \\
(0.26)\end{array}$ & $\begin{array}{l}-1.50 \\
(0.53)\end{array}$ & $\begin{array}{l}-2.14 \\
(0.23)\end{array}$ \\
\hline $\begin{array}{l}\text { Phillips-Perron }{ }^{a} \\
\text { (p-value) }\end{array}$ & $\begin{array}{r}-14.65 \\
(0.00)\end{array}$ & $\begin{array}{l}-6.38 \\
(0.00)\end{array}$ & $\begin{array}{l}-4.76 \\
(0.00)\end{array}$ & $\begin{array}{c}-15.08 \\
(0.00)\end{array}$ & $\begin{array}{r}-10.85 \\
(0.00)\end{array}$ & $\begin{array}{r}-14.11 \\
(0.00)\end{array}$ \\
\hline
\end{tabular}

a - calculated for first differences, ${ }^{b}$ - data re-estimated (compare Álvarez de Toledo et al. (2008)). 
Table 2 compiles the unit root tests results for the particular variables. I apply ADF and Phillips-Perron tests. The ADF test results indicate that the time series are I(1), excluding the unemployment stock and total job seekers stock, which appear to be $\mathrm{I}(0)$. This inference is enhanced by the Phillips-Perron test results.

\section{A single equation model}

The empirical research of the matching function focuses on determining the values of the outflow from unemployment to employment elasticities with respect to the job seekers and vacancies. This focus allows the identification of the matching process character and the indication of the impact of the other variables on the trade process efficiency, e.g., means of the active labor market policy.

Shapiro and Stiglitz (1984) specify the job queuing model of the labor market matching process. The idea of the trade process is based on the unemployment queue. Workers possess perfect information regarding job opportunities. However, workers must wait for new job posts because there is an insufficient number of vacancies. Once new offers are announced, job seekers are randomly assigned to new job posts. The randomness is justified by the large discrepancy between demand and supply. Formally, the matching function takes the form:

$$
M_{t}=m\left(U_{t-1}, v_{t}\right)
$$

where:

$M_{t}$ - outflow from unemployment to employment during month $t$;

$U_{t-1}$ - unemployment stock at the end of month $t-1$ , or $J_{t-1}-$ total job seekers stock at the end of month $t-1$; and

$v_{t}$ - vacancy inflow during month $t$.

I estimate the job queuing matching function using the OLS estimator. The results suffer from high autocorrelation, which is addressed by using the $\mathrm{AR}(1)$

Table 3. Job queuing model estimates, 1994-2005

\begin{tabular}{|c|c|c|c|c|c|c|}
\hline \multirow{2}{*}{$\begin{array}{l}\text { Independent variable } \\
\text { / statistics }\end{array}$} & \multicolumn{6}{|c|}{ Parameters estimates (t-student statistics) } \\
\hline & । & $\rho^{a}$ & IECM & $\|$ & $\|^{\mathrm{a}}$ & $\| \mathrm{ECM}$ \\
\hline $\ln U_{t-1}$ & $\begin{array}{l}0.330 \\
(4.67)\end{array}$ & $\begin{array}{l}0.237 \\
(2.32)\end{array}$ & - & - & - & - \\
\hline $\ln J_{t-1}$ & - & - & - & $\begin{array}{l}0.382 \\
(4.51)\end{array}$ & $\begin{array}{l}0.265 \\
(2.16)\end{array}$ & - \\
\hline $\ln v_{t}$ & $\begin{array}{c}1.069 \\
(41.85)\end{array}$ & $\begin{array}{c}1.033 \\
(27.78)\end{array}$ & - & $\begin{array}{c}1.061 \\
(42.88)\end{array}$ & $\begin{array}{c}1.025 \\
(28.38)\end{array}$ & - \\
\hline$d l n v_{t}$ & - & - & $\begin{array}{c}0.897 \\
(18.35)\end{array}$ & - & - & $\begin{array}{c}0.895 \\
(18.25)\end{array}$ \\
\hline$E C T$ parameter & - & - & $\begin{array}{l}-0.619 \\
(-8.01)\end{array}$ & - & - & $\begin{array}{l}-0.612 \\
(-7.92)\end{array}$ \\
\hline$R^{2}\left(\operatorname{adj} . R^{2}\right)$ & $\begin{array}{l}0.985 \\
0.985\end{array}$ & $\begin{array}{l}0.986 \\
0.986\end{array}$ & $\begin{array}{l}0.745 \\
0.743\end{array}$ & $\begin{array}{l}0.985 \\
0.985\end{array}$ & $\begin{array}{l}0.986 \\
0.986\end{array}$ & $\begin{array}{l}0.743 \\
0.741\end{array}$ \\
\hline $\begin{array}{l}\text { ADF test for residuals } \\
\text { ( } p \text {-value) }\end{array}$ & $\begin{array}{l}-3.95 \\
(0.00)\end{array}$ & $\begin{array}{l}-4.97 \\
(0.00)\end{array}$ & $\begin{array}{l}-4.82 \\
(0.00)\end{array}$ & $\begin{array}{l}-3.87 \\
(0.00)\end{array}$ & $\begin{array}{l}-4.93 \\
(0.00)\end{array}$ & $\begin{array}{l}-4.72 \\
(0.00)\end{array}$ \\
\hline
\end{tabular}

a - equation includes AR(1), dependent variable - outflow from unemployment to employment, ECT - error correction term t-Statistics presented in parentheses 
Table 4. VAR models' diagnostic tests results

\begin{tabular}{lcc}
\hline & $\begin{array}{c}\text { VAR model (job seekers stocks } \\
\text { = unemployment stock) }\end{array}$ & $\begin{array}{c}\text { VAR model (job seekers stocks } \\
\text { = total job seekers stock) }\end{array}$ \\
\hline Lag structure (AIC criterion) & 4 & 2 \\
LM autocorrelation p-value & 0.01 (5th degree) & 0.11 \\
Doornik-Hansen normality test (skewness, joint p-value)
\end{tabular}

The models comprise dummy variables.

Table 5. Cointegration and Granger block exogeneity tests results

\begin{tabular}{lcc}
\hline & $\begin{array}{l}\text { VAR model (job seekers stocks } \\
\text { =unemployment stock) }\end{array}$ & $\begin{array}{c}\text { VAR model (job seekers stocks } \\
\text { = total job seekers stock) }\end{array}$ \\
\hline $\begin{array}{l}\text { Cointegration Rank Test (trace): } \\
\text { no. of cointegrating equations }\end{array}$ & 2 & 1 \\
Granger block exogeneity Wald test, dependent variable & & $10.63(0.03)$ \\
$\chi^{2}$ (p-value): & $18.66(0.02)$ & - \\
- matches & $12.95(0.11)$ & $6.56(0.16)$ \\
- unemployment stock & - & $3.55(0.47)$ \\
- total job seekers stock & $11.98(0.15)$ & \\
- vacancy inflow & & \\
\hline
\end{tabular}

term; the corrected specifications do not provide qualitatively different results. Short-term and long-term multipliers are estimated using Engle-Granger and Engle-Yoo procedures. Model I (in Table 3) refers to the regular job queuing equation; $\mathrm{I}^{\mathrm{a}}$ contains the $\mathrm{AR}(1)$ term, and I ECM checks for a long-term relation and the speed of approaching a new equilibrium. The supply is approximated by the unemployment stock. Models II, II ${ }^{\mathrm{a}}$ and II ECM are analogous; however, they contain total job seekers stock as a supply approximation. All the results for the ADF test show that, at the 5\% significance level, the null hypothesis of the unit root test in the disturbance term should be rejected; therefore, the model approaches long run equilibrium. Overall, the model specifications fit the data reasonably well.

The coefficients express a higher impact of the vacancy inflow on the number of matches than the job seekers pools. This conclusion applies to both long- term and short-term perspectives, in which the vacancy inflow is the sole statistically significant variable that describes the trade between demand and supply. The results do not differ due to the variable approximation of different job seekers pools. The estimated coefficients of the error correction term (ECT) indicate a high speed of achieving equilibrium. On average, equilibrium occurs in less than two months. The Engle-Yoo procedure does not change the results.

\section{A multivariate space analysis}

I develop two VAR models to express the possible trade between the job seekers pools and the vacancies: $M=f(U, v)$ and $M=f(J, v)$. I use the logarithms of the outflow from unemployment to employment, vacancy inflow and job seekers pools (unemployment stock or job seekers stock). The final model specifications are based on the respective 
diagnostic tests (compare Table 4). I analyze the lag structure, the inverse roots of the characteristic AR polynomial and the residuals.

The stability condition is satisfied for both models. The model with the unemployment stock requires 4 lags; the model with total job seekers stock requires 2 lags. The LM autocorrelation tests imply no serial correlation (at the $1 \%$ significance level for the unemployment stock model and at the 5\% significance level for the other model). The Doornik-Hansen skewness test indicates multivariate normal distribution of the residuals.

Next, I perform a cointegration test and a Granger block exogeneity test (compare Table 5). The unemployment stock model experiences 2 cointegrating vectors. The total job seekers stock model experiences one cointegrating vector. The Granger block exogeneity test implies that, in both specifications, only the variable that presents the number of matches should be treated as the endogenous variable. The others are exogenous. Pairwise Granger causality tests indicate, at the 5\% significance level, that the unemployment stock influences the outflow from unemployment to employment as does the vacancy inflow. Nevertheless, the job seekers stock does not influence the outflow from unemployment to employment and the inverse relation does not hold. Then, the results question the relevance of a multivariate space analysis.

\section{Discussion}

I have encountered two papers that refer to non-stationary data in analyzing labor market matching in Spain. Bell (1997) performs comparative analysis of the matching process in three European countries, including Spain. She adopts a general dynamic error correction regression specification with differences and lagged levels of the dependent and explanatory variables. Gałecka-Burdziak (2013) uses two-step Engle-Granger and three-step Engle-Yoo procedures. In both papers, the unemployment negatively influences the matching process, whereas the impact of vacancies is positive.

The diagnostic tests of the VAR models question the analysis of a public intermediation matching process in the Spanish labor market. It appears that the outflows from unemployment are explained by the number of agents present in the labor market; however, the inverse relation does not hold.
Thus, the single equation model estimates appear to provide consistent results. However, one must remember that the Engle-Granger procedure provides one cointegrating vector. If there are more such vectors, the outcome may constitute a linear combination of the basis vectors (Welfe 2009). The quantitative results show that demand appears to be the driving force in the job creation process that occurs through public employment intermediation, which is in accordance with previous analyses. ECT estimates express the high efficiency of the market. For a comparison, we can recall the Berman (1997) and Gałecka-Burdziak (2013) analyses. Berman (1997) performs estimates and simulations of the matching process in the Israeli labor market. He finds the job search process to be extremely efficient; the labor market absorbs shocks within less than a few months. Gałecka-Burdziak (2013) obtains comparable results (less than a few months) for the Polish and Spanish labor markets. The equilibrium in the matching function concept is defined by the equity of inflows and outflows from unemployment. High efficiency may reflect the large volatility of the market and a permanent adjustment process.

\section{Conclusions}

I conduct quantitative analysis of the labor market matching process in Spain during the 1994-2005 time period. This time span reflects an upward movement along a Beveridge curve; therefore, we can expect homogenous trade technology. I refer solely to public employment intermediation by using registered unemployment data. I focus on the problem of non-stationary data. I conduct multivariate space analysis and use a single equation model. The results are, in general, consistent with the literature findings.

The number of matches, the outflow from unemployment to employment, increases when new job offers are registered at public employment offices. The demand role in generating matches is unquestionable. However, it should be emphasized that the number of matches is computed on the basis of the number of covered job posts.

Supply's role is much smaller; therefore, the workers exert a higher congestion effect on each other. Job seekers compete for job offers. The relevance of the job queuing model confirms that job seekers are randomly ascribed to new job offers. There arises the need to 

